\title{
Publisher Correction: Side chain determinants of biopolymer function during selection and replication
}

Phillip A. Lichtor (D), Zhen Chen, Nadine H. Elowe, Jonathan C. Chen (D) and David R. Liu (D)

Correction to: https://doi.org/10.1038/s41589-019-0229-2, published online 11 February 2019.

In the version of this article originally published, several data points in Fig. 4c were shifted out of place during production. The corrected version of Fig. $4 \mathrm{c}$ is shown below. This error has been corrected in the PDF and HTML versions of the article.

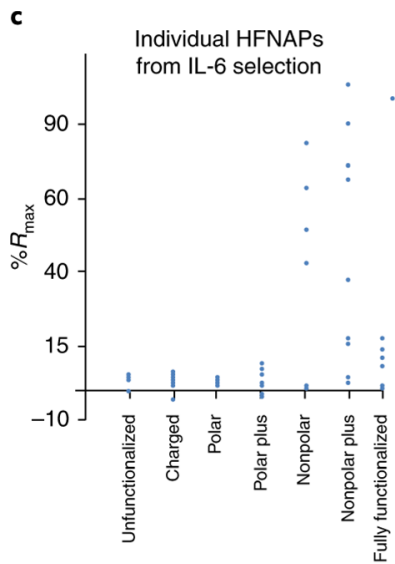

Original

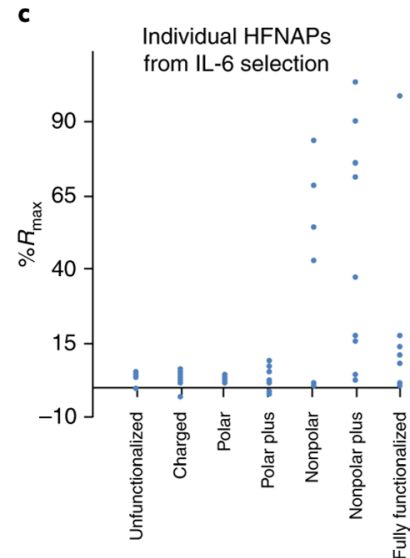

Corrected

Fig. 4c | Original and Corrected.

Published online: 11 March 2019

https://doi.org/10.1038/s41589-019-0254-1 